\title{
25 Research Square

\section{Mental Health and Mining Dam Rupture: a qualitative study on impacts to affected people in a city in Brazil}

Marcela Alves de Lima Santos ( $\square$ marcela_lima5@hotmail.com )

René Rachou Institute - Fundação Oswaldo Cruz Minas https://orcid.org/0000-0002-7579-8067

Celina Maria Modena

René Rachou Institute - Fundação Oswaldo Cruz Minas

\section{Research article}

Keywords: disasters, mental health, public health

Posted Date: February 3rd, 2020

DOl: https://doi.org/10.21203/rs.2.22430/v1

License: (c) (1) This work is licensed under a Creative Commons Attribution 4.0 International License.

Read Full License 


\title{
Mental Health and Mining Dam Rupture: a qualitative study on impacts to
} affected people in a city in Brazil

\author{
Marcela Alves de Lima Santos - René Rachou Institute - FIOCRUZ-Minas \\ Celina Maria Modena - René Rachou Institute - FIOCRUZ-Minas
}

\section{Correspondence:}

Marcela Alves de Lima Santos

E-mail: marcela_lima5@hotmail.com

René Rachou Institute - FIOCRUZ-Minas, Augusto de Lima Avenue, 1715, Barro Preto, Belo Horizonte, Minas Gerais, CEP 30190-002, Brazil. 


\title{
Mental Health and Mining Dam Rupture: a qualitative study on impacts to affected people in a city in Brazil
}

\begin{abstract}
- Background: In 2015, a technological disaster occurred through a mining dam rupture in the municipality of Mariana, state of Minas Gerais, Brazil. In addition to impacts on the environment, there were 19 deaths and displacements of approximately 300 families. The purpose of the study is to investigate the perception of psychosocial impacts on the population affected by this disaster from the perspective of different groups involved and to suggest guidelines for the construction of mental health interventions in this context.

- Methods: The study was conducted during the period of 2015 to 2019 from the perspective of qualitative research using participant observation, focus groups and individual interviews. Participants were people affected by the disaster, mental health workers and school professionals. Content Analysis was used to analyze the data.

- Results: These families lost material, cultural, heritage, and symbolic assets. They were also forcibly displaced from rural to urban areas. The results showed loss of autonomy, difficulty in adapting to the new territory, reduced social support and suffering with hostility and stigma. In addition, they suffer from delay and waiting for resettlement.

- Conclusions: Understanding the context is important for building mental health actions in disaster recovery. The study results show vulnerabilities and weaknesses in a post-disaster scenario. Understanding the social and community aspects involved enables mental health interventions based on the demands and capabilities of the population itself.
\end{abstract}

- Keywords: disasters, mental health, public health.

\section{Background}

Disaster risk reduction remains a major global challenge. The 2015-2030 Sendai Milestone aims to substantially reduce these episodes and the losses caused by them. In 
addition, it aims to adopt measures that reduce exposure to vulnerability threats from disasters, increase preparedness for better response and recovery, thereby enhancing resilience capacity ${ }^{1}$

Disasters are characterized by a severe disruption of the functioning of a community or society that causes major human, material, economic or environmental loss and impacts that exceed the ability of the affected community or society to deal with the situation through its own resources ${ }^{2}$.

This study will investigate impacts on the mental health of people affected by the rupture of the mining dam owned by mining company Samarco S.A. and its maintainers VALE S.A. and BHP Billiton in 2015, in the municipality of Mariana, state of Minas Gerais, Brazil. This is a technological disaster, that is, caused by human action, where approximately 34 million $\mathrm{m}^{3}$ of iron ore tailings were dumped into the environment, causing 19 deaths and destruction in more than 30 municipalities in two Brazilian states: Minas Gerais and Espírito Santo ${ }^{3}$.

Approximately 300 families have lost material, heritage, cultural and symbolic assets. In addition, they were forced to withdraw from the rural area where they lived, where many were born and built their affective bonds ${ }^{4}$. Amid this scenario of loss, affected populations also suffer from damage to mental health. In this case, it is necessary to understand the health condition of the population so that effective response and recovery strategies are built.

However, there are still few studies that deal with these impacts qualitatively and considering the social determinants in health involved in disasters with displacement of people and rupture of various bonds. Most studies address the issue from quantitative analyzes of what types of diseases have been developed in the medium and long term ${ }^{5,6,7,8}$. Thus, the qualitative analysis contributes to the deepening and better understanding of the effects on mental health in affected people.

This study aims to investigate the perception of psychosocial impacts on the population affected by this disaster from the perspective of different groups involved and to suggest guidelines for the construction of mental health interventions in this context.

\section{Methods}

The qualitative method was chosen because it allows the understanding of the meanings attributed by the participants to the studied phenomenon ${ }^{9,10,11}$. The fieldwork was carried out using the following methods: participant observation ${ }^{12}$, focus groups ${ }^{13}$ with mental health workers and professionals from schools impacted by the disaster and individual 
interviews ${ }^{9}$ with affected people. Data were collected between January 2016 and September 2019 as part of the first author's doctoral student project that investigates the impacts and health care of people affected by the disaster that occurred in 2015 .

The study was conducted in the city of Mariana, which is located in the central region of Minas Gerais State, southeastern region of Brazil. The estimated population for the year 2019 is 60,724 people $^{14}$. It is a city that has strong economic dependence on mining activity. After the disaster, families were abruptly displaced from the affected rural areas to the urban area of the municipality. Health facilities and schools also needed to be transferred to serve this population ${ }^{4}$. Thus, the research locations were health services, schools and community spaces frequented by the affected people.

Participants were people affected by this disaster, mental health workers who participate directly on interventions with these families, and professionals from both schools that were destroyed in this tragedy.

The first author is inserted in the municipality as of the occurrence of the dam rupture to the present day. Data collection began with participant observation by monitoring the activities of affected people in different areas of the city and by building workers' actions in mental health services and schools. Through this procedure, it is possible to identify other elements that are not captured through speech and writing ${ }^{\mathbf{1 5}}$.

Focus groups and individual interviews were conducted in the participants' workplaces based on semi-structured interviews. The objective was to understand the different participants' perceptions about the mental health impacts of the people affected by the disaster and to allow a reflection upon this new reality. Working with focus groups is an important technique because it allows the understanding of processes of reality construction, daily practices, reactions to facts and events, as well as behaviors and attitudes ${ }^{\mathbf{1 6}}$.

In this article, the voices and experiences of the different actors involved in this disaster are presented and analyzed, also the researcher's participant observation of the affected families. For data analysis, the content analysis technique was used ${ }^{17}$.

Ethical approval was obtained from the Research Ethics Committee of the René Rachou Institute under protocol CAAE 53911916.0.0000.5091, by the Municipal Health Department and the Municipal Education Department of Mariana. All participants signed the Informed Consent Form and were advised that their participation was voluntary, and that anonymity would be guaranteed.

\section{$\underline{\text { Results }}$}




\section{Abrupt withdrawal and losses}

With the rupture of the Fundão dam, the affected people had to leave the places where they lived suddenly and quickly. Reports show that there was no plan or route for escape, showing the absence of prevention and preparedness actions with these communities.

"Everybody was running and screaming; run people, go out people. We didn't know where the mud was coming from, whether it could catch us or not. Whether we would live or not, who survived, who's alive, where such and such is. This was total despair." (Report of affected person)

Along with this displacement, families experience a series of material and symbolic losses. They can no longer perform some meaningful activities for them and begin to live with restrictions and decreased functionality.

"Because before, they had the garden they planted for their own support or to sell in the city; they had cattle, they had the animals they cared for. And today they are in apartments where they can't hammer a nail to the wall. The garden, they can't have. So, they are resentful" (Reporting by mental health professional)

\section{The new territory}

After being moved to the urban area, affected families were placed in houses or apartments rented by the company responsible for the disaster. Besides being in a very different territory from the one they lived before, they were also in different neighborhoods and distant from family and friends.

"In the first contacts, when we went to the families, we went from house to house to know how they were doing. We heard a lot from family members and adolescents about the difficulties in this new territory and to circulate here. Many parents who are very afraid of their children moving around here in the city because it was larger than the rural district, more dangerous, more violent, from their perspective of the district."(Reporting by a mental health professional)

The reports also show how affected people have difficulty adapting to this place, especially not recognizing that space as their own. In this new territory, the reports are of nonbelonging. Given this scenario, there is a difficulty in adapting to this new place.

"This is not my house. It was not the investment I made. Why do I have to go to a church, if that is not the church where I see my neighbors and my friends? I don't feel well in that place."(Mental health professional reproducing speech he heard from an affected person) 


\section{Loss of Autonomy}

Moving to the urban area also results in loss of autonomy. The sudden changes in geographical location, the distance between families and all other losses, create restrictions on the lives of those affected.

In the case of children and adolescents, they talk about the lack of freedom due to the difficulty of traveling, the fear of violence in the city and the fear of contact with strangers.

"In the case of children, it is the matter of freedom. They all have a relationship there where we lived, but here they do not have. It is an apartment or a house with small space. And there, it was a street, a big yard, a soccer field, a square. This is the difference. There, I knew everyone, the schools. It's a huge difference! And, then, it was starting from scratch." (Report of affected person)

Among the elderly, many were able to perform their daily activities independently, some lived alone. After the disaster, they are more restricted to their home environment and more dependent on others in their daily lives.

"He would get up in the morning and go to a garden, to milk the cow; he would move around in his space with autonomy. Today, he is no longer able to do this because he ends up depending on other people to go to a market, go to the doctor, make a purchase or visit another relative. And so, today, they no longer have this autonomy."(Mental Health Professional Report)

\section{Social support}

In rural districts, there was a social support network. As those were small places, people knew each other and could share a care for each other, especially with children and the elderly. The community itself knew its points of weakness and vulnerability. After the disaster, this contact is hindered, evidencing a break in these social bonds.

"Often they fail to visit a former neighbor who is in a more distant neighborhood. To get around, sometimes they don't know how to take a bus. Sometimes he has difficulty with mobility, which makes it difficult for him to circulate with more development, with more autonomy. It has everything that restricts them to the home, and it really makes to lose a lot of meaning of life."(Reporting from a mental health professional)

"Some were frailer, and the neighbors would go there and give a plate of food, give medication, take care, cut their hair. Then, they had a very strong connection. And that was lost after the dam broke because each one went to live in a different corner." (Reporting by a mental health professional)

\section{Hostility and stigma}


Affected people report that they suffered from prejudice and stigma a few months after the disaster struck. They were identified as out-of-town people and as people from "Bento", the rural area most affected by the disaster. In addition, because they were receiving reparation benefits from mining companies, they were called profiteers by some urban dwellers.

"They say: they are profiteers and they are taking everything from the company. And that's not it; we are getting what is right. If it were not, the company would not pay."(Report of affected person)

"And there was a certain prejudice with them too, which we didn't know when it was generated, but it existed." (Report from school professional)

\section{The wait for resettlement}

The whole population suffers from anguish and anxiety waiting for a new place. In the case of the elderly, the talk about the fear of dying and not experiencing this new home is more frequent.

"The reason for their fear; their speech goes like this, 'Wow! So-and-so died! There wasn't even time to wait for his house. Wow! So-and-so will die. And I'm going to die too because I'm feeling it; I'm feeling anguish; I'm feeling depression; I have panic syndrome. And there it goes, adding up, summing up"(Report of a mental health professional)

Children and adolescents also show a desire to return to community life and the fear that this will not happen.

"It's another problem, another problem is this insecurity. They are dreaming of resettlement, but at the same time already want to have a 'plan B.' They are fearful." (Report from school professional)

\section{$\underline{\text { Discussion }}$}

Results show the importance of understanding the context for good performance in a disaster situation. Xi et al. ${ }^{18}$ point out that this information includes the type of disaster and its geographic reach, the affected population, local cultural characteristics and information about local mental health network resources, as well as their difficulties in interventions.

In a review of five different situations, Luchinni et al. identify the need for long-term health care building for affected populations ${ }^{19}$. Levine et al., in a study on displaced populations due to disasters, conclude that it is necessary to understand more about long-term mental health performance in this context and to consider the complex interaction between 
vulnerability, social relations and housing from an integral approach ${ }^{20}$. The reports presented here indicate factors that need to be considered to support the construction of longitudinal actions with these communities and may also be a reference for other displacement situations resulting from disasters.

When we analyze the impact after the disaster, we find that for those affected, life in Mariana's urban area is limited and dependent. One of the main reasons for this limitation is the displacement of their houses in the rural area to be allocated in the urban area. In other disasters, displacement is marked as a factor in increasing the prevalence of psychological problems. For example, in the study by Yzermans et al., this prevalence was approximately twice as high in people who had to relocate as compared to un-relocated victims ${ }^{21}$.

Munro et al. studied mental health impacts on persons displaced after flooding in 2013 and 2014 in England. In this cross-sectional study, an association was found between displacement and reported symptoms of depression, anxiety, and posttraumatic stress disorder one year after flooding. This study also showed the amount of warning received before displacement as a protective factor showed evidence of protection against the symptoms of these three mental illnesses. Analysis of the reports in Mariana shows that there was no warning and people had to leave their properties abruptly. Thus, it is possible to state that this is another point of vulnerability of the mental health condition to which these communities were subjected.

In a qualitative analysis of mental health concerns after the triple disaster in March 2011 in Japan, the loss of housing and property in Fukushima City was also identified as a significant problem ${ }^{22}$. The authors also point out that feelings of belonging and community are essential elements for mental well-being.

At this point, it is important that this territory be understood not only as an overlapping of a set of natural systems and a set of systems of things created by man, but as the identity, fact and feeling of belonging to what belongs to $\mathrm{us}^{23}$. This concept allows us to approach the reality identified in the speech of those affected who are displaced, suffer losses in various dimensions and fail to recognize themselves in this new place.

A population is found that has its habits, housing and functions completely modified. Many of these restrictions on such meaningful activities as planting on your own land and breeding animals cause loss of the meaning of life. With so many restrictions and vulnerabilities, those affected suffer from loss of autonomy, have difficulty moving around the city, and performing their activities alone.

Social support is identified as a factor mediating the long-term effects on the suffering 
of the disaster-exposed population ${ }^{24,25}$. The importance of social support is also discussed in the study by Bryant et al. who analyzed social networks and the relationship to post-disaster mental health problems such as depression and post-traumatic stress disorder (PTSD) in victims of forest fires that affected most of Victoria State, in Australia, in February $2009^{26}$. The authors found that the risk of depression was higher in participants who reported fewer social connections, were connected to other depressed people, or were linked to people who left their community. The risk of PTSD was higher if fewer people reported being connected with the participant, if those who felt close to the participant had higher levels of property loss or if the participant was linked to others who were not interconnected. In addition, being connected to others who were in turn close to each other was associated with a lower risk of PTSD.

Among the elderly, the concern is great since some studies show that people in this age group are disproportionately affected in disaster situations ${ }^{27}$. These authors also found in a review study on the theme that social support, individual health condition and functionality are factors that influence the resilience of the elderly in the stages of preparedness, response and recovery in disasters.

In the disaster in Mariana, we found people who had their social, family and community ties fragmented. In addition, they lost their properties in the rural area and moved to homes far from their families. Therefore, considering these studies that address the importance of social networks for mental health and disaster recovery, it is important to understand the social factors and intervention in strengthening these links to act in this context.

Silove et al. state that psychosocial recovery in an emergency care context needs an approach that enables the community to recreate a cohesive and secure society ${ }^{28}$. They argue that well-designed reconstruction programs must address aspects of the psychosocial, economic and cultural realm, and that the community itself needs to be at the forefront of supporting its own members, as they already know and share the same culture, beliefs and values.

Although not directly discussing the impact on health services, it is possible to foresee an increase in demand in this context. As shown in the study by Munro et al., displacement has consequences not only for affected areas, but also for the areas where these people are allocated ${ }^{5}$ Thus, there is a change in the configuration of mental health care services and the need to build care models focused on the health needs of this new audience.

Another issue that appears in the study is the stigma and prejudice suffered by this 
population. In Mariana, these people were pointed out as profiteers because they were receiving reparation benefits after the disaster. A similar situation was found in the study by Adam Kars et al. where they show that the displaced population after the disaster in Japan and who were in government-subsidized housing also suffered from stigmatization ${ }^{22}$.

In addition to all these factors, those affected report the anguish and insecurity of waiting for resettlement. Four years after the disaster, families are still temporarily allocated to urban areas. Upon completion of the construction of houses on other land, they will be relocated and find a new territory. Considering all the damage to mental health arising from displacement situations previously presented, attention is needed to this new scenario that is formed. There is still a gap regarding research that looks at mental health conditions after the resettlement of disaster-affected communities and the possible approaches at that time of reconstruction.

As this is a qualitative research, the findings refer to perceptions of different actors involved in this disaster. The fact that it is based on participants reports can be presented as a limitation. However, the study points to important indications for understanding this context and for the construction of interventions in the mental health area in the context of disasters. Further research may be conducted in different contexts to see if similar results are found.

\section{Conclusions}

The study results show vulnerabilities and weaknesses in a post-disaster scenario. Understanding the social and community aspects involved enables mental health interventions based on the demands and capabilities of the population itself. Thus, it is possible to develop large recovery projects in which these communities can be protagonists in the construction of alternatives based on their culture and values.

From this perspective, people who may have chronic and disabling diseases can also be better diagnosed and followed, as it is expected that most of the population does not require this specialized support. The study is relevant because it enables a broader understanding of the disaster situation and points out the potential for development of action based on an expanded concept of mental health, based on social and community interventions.

\section{List of abbreviations}

PTSD - Posttraumatic Stress Disorder 


\section{$\underline{\text { Declarations }}$}

\section{Ethics approval and consent to participate}

Ethical approval was obtained from the Research Ethics Committee of the René Rachou Institute under protocol CAAE 53911916.0.0000.5091, by the Municipal Health Department and the Municipal Education Department of Mariana. All participants signed the Informed Consent Form and were advised that their participation was voluntary, and that anonymity would be guaranteed. Information about the study, potential harms and benefits, the purpose of the study and the right to withdraw were emphasized, both in the written material and directly to the homeless population before the interviews started.

\section{Consent for publication}

Not applicable

\section{Availability of data and materials}

The data that supports the findings of this study will not be made publicly available, due to participant confidentiality restrictions. Interested investigators may contact the researchers to explore data sharing options.

\section{Competing interests}

The authors declare that they have no competing interests

\section{Funding}

This research was funded by the René Rachou Institute - Fiocruz Minas. This institute was responsible for funding the process of translating this manuscript.

\section{Authors' contributions}

MALS and CMM contributed to the study design, conducted the interviews and analyzed the data, reviewed the relevant literature, drafted the manuscript and approved the final manuscript.

\section{Acknowledgements}


We would like to thank the interview participants for sharing their experiences, stories and knowledge.

\section{Authors' information}

Affiliations: René Rachou Institute - Fiocruz Minas, Augusto de Lima Avenue, 1715, Belo

Horizonte, Minas Gerais, CEP: 30190-002, Brazil

\section{References}

1. UNISDR, United Nations International Strategy for Disaster Reduction. Marco de Sendai para la Reducción del Riesgo de Desastres 2015-2030.

2. UNISDR, United Nations International Strategy for Disaster Reduction. Terminology on Disaster Risk Reduction. Geneva, Switzerland, May 2009. Available at: https://www.unisdr.org/files/7817 UNISDRTerminologyEnglish.pdf.

3. Brazil. Laudo Técnico Preliminar: Impactos ambientais decorrentes do desastre envolvendo o rompimento da barragem de Fundão, em Mariana, Minas Gerais, Instituto Brasileiro do Meio Ambiente e dos Recursos Naturais Renováveis - IBAMA. Brasília, 2015.

4. Santos MAL, Rossi, SR. A construção do cuidado psicossocial aos atingidos do desastre de Mariana (MG): um relato de experiência. In: Sant'anna Filho O., Lopes DC. O psicólogo na redução dos riscos de desastres: teoria e prática. Editora Hogrefe Cetepp, São Paulo, 2017 p.185-196.

5. Munro A, Kovats RS; Rubin, GJ; Waite, TD, Bone A, Armstrong B and the English National Study of Flooding and Health Study Group. Effect of evacuation and displacement on the association between flooding and mental health outcomes: a cross-sectional analysis of UK survey data. Lancet Planet Health, 2017; 1(4):e134-e141.

6. Schwartz RM, Gillezeau CN, Liu B, Lieberman-Cribbin W and Taioli E. Longitudinal Impact of Hurricane Sandy Exposure on Mental Health Symptoms. Internacional Journal of Environmental Research Public Health, 2017, 14, 957.

7. Schwartz RM. Rasul R, Kerath SM, Watson AR, Lieberman-Cribbin W, Liu B, Taioli E. Displacement during Hurricane Sandy: The impact on mental health. Journal of Emergency Management, 2017, 16(1):17-27.

8. Lieberman-Cribbin W, Liu B, Schneider S, Schwartz R, Taioli E. Self-Reported and FEMA Flood Exposure Assessment after Hurricane Sandy: Association with Mental Health Outcomes. PLoS ONE, 2017, 12(1): e0170965. https://doi.org/10.1371/journal.pone.0170965.

9. Flick U. Desenho da pesquisa qualitativa. Porto Alegre: Artmed, 2009.

10. Denzin NK, Lincoln YS. O planejamento da pesquisa qualitativa: teorias e abordagens. $2^{\mathrm{a}}$. ed. Porto Alegre: Artmed, 2006. 
11. Minayo MCS. O desafio do conhecimento: Pesquisa Qualitativa em Saúde. $14^{a}$ edição. Hucitec Editora, São Paulo, 2014.

12. Angrosino M. Etnografia e Observação Participante. Editora Artmed: Porto Alegre; 2009.

13. Barbour R. Grupos Focais. Editora Artmed: Porto Alegre, 2009.

14. IBGE. Instituto Brasileiro de Geografia e Estatística.

https://cidades.ibge.gov.br/brasil/mg/mariana/panorama. Accessed 14 december 2019.

15. Victora CG; Knauth DR; Hassen MNA. Pesquisa Qualitativa em Saúde: uma introdução ao tema. Porto Alegre; Tomo Editorial; 2000, 133p.

16. Gatti, B.A.G. Grupo focal nas pesquisas em Ciências Sociais e Humanas. Série Pesquisa. Liber Livro Editora, Brasília, 2012

17. Bardin, L. Análise de Conteúdo. Editora Edições 70, São Paulo, 2008.

18. Xi Y, Chen R, Gillespie AL et al. Mental health workers perceptions of disaster response in China. BMC Public Health 19, 11 (2019). doi:10.1186/s12889-018-6313-9

19. Lucchini RG, Hashim D, Acquilla $\mathrm{S}$, et al. A comparative assessment of major international disasters: the need for exposure assessment, systematic emergency preparedness, and lifetime health care. BMC Public Health. 2017;17(1):46. doi:10.1186/s12889-016-3939-3

20. Levine J, Esnard, A, Sapat A. Population Displacement and Housing Dilemmas Due to Catastrophic Disasters. Journal of Planning Literature, 2007, p.3-15. doi: $10.1177 / 0885412207302277$.

21. Yzermans CJ, Donker GA, Kerssens JJ, Dirkzwager AJE, Soeteman RJH, ten Veen PMH. Health problems of victims before and after disaster: a longitudinal study in general practice, International Journal of Epidemiology, 2005, p. 820-826. https://doi.org/10.1093/ije/dyi096.

22. Karz A, Reichstein J, Yanagisawa R, MD, Katz CL. Ongoing Mental Health Concerns in Post-3/11 Japan. Annals of Global Health, 2014, 80(2):108-14. doi: 10.1016/j.aogh.2014.04.005.

23. Santos M. Por uma outra globalização - do pensamento único à consciência universal. $5^{\mathrm{a}}$ edição. Rio de Janeiro: Record, 2001.

24. Norris FH, Kaniasty K. (1996). Received and perceived social support in times of stress: A test of the social support deterioration deterrence model. Journal of Personality and Social Psychology, 71(3), 498-511.http://dx.doi.org/10.1037/0022-3514.71.3.498.

25. Koyama S, Aida J, Kawachi I, Kondo N, Subramanian SV, Ito K, Kobashi G, Masuno K, Kondo K, Osaka K. Social Support Improves Mental Health among the Victims Relocated to Temporary Housing following the Great East Japan Earthquake and Tsunami. Tohoku J. Exp. Med., 2014, 234 (3), 241-247. 
26. Bryant RA, Gallagher C, Gibbs L, Pattison P, MacDougall C, Harms L, Block K, Baker E, Sinnott V, Ireton G, Richardson J, Forbes D, Lusher D. Mental Health and Social Networks After Disaster. Am J Psychiatry, 2017, 174(3), p.277-285. https://doi.org/10.1176/appi.ajp.2016.15111403.

27. Kwan C, Walsh CA. Seniors' disaster resilience: A scoping review of the literature, International Journal of Disaster Risk Reduction, 2017. http://dx.doi.org/10.1016/j.ijdrr.2017.09.010.

28. Silove D, Steel Z, Psychol M. Understanding community psychosocial needs after disasters: Implications for mental health services. J Postgrad Med 2006; 52:121-5. 